\title{
Influence of Calcium Ions on Cell Survival and Proliferation in the Context of an Alginate Hydrogel
}

\author{
N. Cao, ${ }^{1}$ X. B. Chen, ${ }^{1,2}$ and D. J. Schreyer ${ }^{1,3}$ \\ ${ }^{1}$ Division of Biomedical Engineering, University of Saskatchewan, Saskatoon, SK, Canada S7N 5A9 \\ ${ }^{2}$ Department of Mechanical Engineering, University of Saskatchewan, Saskatoon, SK, Canada S7N 5A9 \\ ${ }^{3}$ Department of Anatomy and Cell Biology, University of Saskatchewan, Saskatoon, SK, Canada S7N 5E5
}

Correspondence should be addressed to X. B. Chen, xbc719@mail.usask.ca

Received 1 February 2012; Accepted 9 April 2012

Academic Editors: G. D’Errico and H. Domínguez

Copyright (C) 2012 N. Cao et al. This is an open access article distributed under the Creative Commons Attribution License, which permits unrestricted use, distribution, and reproduction in any medium, provided the original work is properly cited.

\begin{abstract}
One goal of biofabrication is to incorporate living cells into artificial scaffolds in order to repair damaged tissues or organs. Although there are many studies on various biofabrication techniques, the maintenance of cell viability during the biofabrication process and cell proliferation after the process is still a challenging issue. Construction of scaffolds using hydrogels composed of natural materials can avoid exposure of cells to harsh chemicals or temperature extremes but can still entail exposure to nonphysiological conditions, causing cell damage or even death. This paper presents an experimental investigation into the influence on Schwann cell survival and proliferation of calcium used for ionic crosslinking of alginate hydrogel during the biofabrication process. The experimental results obtained show the viability and proliferation capacity of cells, either suspended in cell culture medium or encapsulated in hydrogel, and vary with the calcium concentration and the time period of cells exposed to the calcium environment. The experimental results also show the alginate concentration and cell density, that have profound influence on cell survival and proliferation, and solution viscosity as well. This study suggests the incorporation of living cells in calcium-crosslinked hydrogel in the biofabrication process can be regulated for controlled cell survival and proliferation.
\end{abstract}

\section{Introduction}

Biofabrication aims to incorporate living cells into constructs such as the artificial scaffolds used to repair damaged tissues or organs. Dispensing-based cell deposition, in which pneumatic or other volumetrically driven dispensers are used to deposit the material, is considered to be a promising technique for biofabrication because of its fast and efficient material processing and manipulating capacity and has been widely employed in various tissue-engineered scaffold fabrication. However, there are various potential sources for cell damage in dispensing process, which makes the incorporation and manipulation of living cells a challenging task $[1,2]$. Previous studies have investigated the influence of process-induced mechanical force on cell damage/survival $[3,4]$. Both decreasing nozzle diameter and increasing applied dispensing air pressure were found to increase mechanical stresses, thus decreasing cell viability. In order to achieve the goal of incorporating living cells into artificial tissue scaffolds, research into the cell damage caused by other sources during and after the fabrication process is essential.

Alginate is a naturally derived polymer, which has been wildly employed in dispensing-based biofabrication for various applications such as nerve tissue engineering $[5,6]$ and bone tissue engineering $[7,8]$, because of its good biocompatibility and ease gelation in the presence of calcium ions $[5,9,10]$. And calcium ions have been used to crosslink alginate in order to form hydrogel in dispensing-based biofabrication process. Although hydrogel formation through calcium crosslinking is a critical step in the fabrication process and has been utilized by researchers for a long time, the influence of calcium ions on cell damage/survival has not been well documented. This paper reports our experimental study on the viability and proliferation capacity of cells, either suspended in cell culture medium or encapsulated in alginate hydrogel, by varying the calcium concentration and the time period of cells exposed to the calcium environment. The influence of alginate concentration and cell density 
on cell viability and proliferation during and after the fabrication process as well as the solution viscosity were also investigated by experiments. In the present study, Schwann cells were chosen for use in the experiments because of their wide applications in nerve tissue engineering $[11,12]$.

\section{Materials and Method}

2.1. Preparation for Schwann Cells. A Schwann cell line (RSCs 96, CRL 2765) was purchased from American Type Culture Collection (Manassas, VA, USA), at passage nine. Cells were harvested between passage number nine and thirteen for all experiments in this paper. Then cells were maintained in standard Dulbecco's Modified Eagle Medium (DMEM) supplemented with 10\% fetal bovine serum (FBS) (Invitrogen Co, Carlsbad, CA, USA) and grown in $10 \mathrm{~cm}$ tissue culture dishes at $37^{\circ} \mathrm{C}$ in a $5 \% \mathrm{CO}_{2}$, humidified environment. The media were changed every other day. At 100 percent confluency, cells were washed with $1 \mathrm{~mL} 0.25 \%$ Trypsin/EDTA (Invitrogen) for 1 min to detach the cells from the dish. Then cell suspensions were delivered into a sterile $15 \mathrm{~mL}$ falcon tube and centrifuged at $800 \mathrm{RPM}$ in a centrifuge for $5 \mathrm{~min}$. Cells were counted and resuspended in fresh media to the desired cell density.

2.2. Cell Culture and Calcium Treatment. Cell suspensions, as prepared above, were placed in the wells of a 96-well plate at a density of $2 \times 10^{5}$ cells $/ \mathrm{mL}$, with a volume of $100 \mu \mathrm{L}$ for each well. Calcium chloride (Sigma, St. Louis, MO, USA) was dissolved in DMEM at concentrations of $100 \mathrm{mM}, 500 \mathrm{mM}$, or $1 \mathrm{M}$, respectively. The solutions were filter sterilized by a $0.2 \mu \mathrm{m}$ filter, and then were added into cell cultures. After various time periods of 5, 10, 30 minutes, the solution in each well was carefully removed, only leaving the Schwann cells attached to the well. Attached Schwann cells were washed three times with DMEM, covered again with medium, and then incubated at $37^{\circ} \mathrm{C}$ in a $5 \% \mathrm{CO}_{2}$ humidified environment for a time period of 6 or 24 hours. In some wells, cells were allowed to grow without any alginate hydrogel as control group. The cell media were refreshed every other day.

\subsection{Alginate Preparation and Encapsulation of Schwann Cells.} Low viscosity sodium alginate (Sigma, St. Louis, MO, USA), which has an $\mathrm{M} / \mathrm{G}$ ratio of 1.56 and a molecular weight range $12,000 \sim 80,000 \mathrm{Da}$, the molar fraction of guluronic acid is approximately 0.39 and was employed for all the studies in this paper and sterilized by gamma radiation for 18 hours. The alginate solution was prepared from sterilized sodium alginate powder by dissolving in DMEM with 10\% FBS to make stock solution at various concentrations.

Cell suspension, as prepared above, was added to alginate solution at various volume ratios in order to get alginate solution at final concentration of $2 \%$ and $4 \%(\mathrm{w} / \mathrm{v})$ with cell density of $2 \times 10^{5}$ cells $/ \mathrm{mL}, 4 \times 10^{5}$ cells $/ \mathrm{mL}, 6 \times$ $10^{5}$ cells $/ \mathrm{mL}, 8.5 \times 10^{5}$ cells $/ \mathrm{mL}$, and $4 \times 10^{6}$ cells $/ \mathrm{mL}$ for different studies, respectively. Then, the cell-alginate suspension was placed on the bottom of wells of a 96-well tissue culture plate with a volume of $100 \mu \mathrm{L}$ per well. Calcium chloride solutions, formed as above, were then added into the wells to crosslink the cell-alginate suspension, to form hydrogels. Thirty minutes later, the hydrogels were rinsed three times and then submerged, and incubated in DMEM at $37^{\circ} \mathrm{C}$ in a $5 \% \mathrm{CO}_{2}$, humidified environment. In some wells, cells were allowed to grow without any alginate hydrogel as control group. The cell media were refreshed every other day.

All these operations were done in a sterilized environment inside of a clean bench.

2.4. MTT Assay for Cell Damage. MTT assay was used to measure and evaluated cell survival and proliferation in this study. MTT (3-(4,5-Dimethylthiazol-2-yl)-2,5diphenyltetrazolium bromide) is reduced to purple formazan in living cells. A solubilization solution (either dimethyl sulfoxide, an acidified ethanol solution, or a solution of the detergent sodium dodecyl sulfate in diluted hydrochloric acid) was added to dissolve the insoluble purple formazan reaction product. The absorbance of this colored solution can be measured at a certain wavelength (usually between 500 and $600 \mathrm{~nm}$ ) using a SpectrMax 250 Monochromatic spectrophotometer (GMI Inc, Minnesota, USA). In this study, MTT was dissolved in PBS and filter sterilized to obtain a stock solution with a concentration of $5 \mathrm{mg} / \mathrm{mL}$. A solution of $4 \mathrm{mM} \mathrm{HCl}, 0.1 \%$ Nondet P-40 (NP40) in isopropanol, was used as the MTT solvent.

Cells encapsulated with alginate gels were cultured in a three dimensional (3D) condition. Hydrogels made from $100 \mu \mathrm{L}$ alginate solution with a concentration of $2 \%(\mathrm{w} / \mathrm{v})$ and $4 \%(\mathrm{w} / \mathrm{v})$, respectively, were placed in the wells of a 96-well plate. The cell suspensions in the wells, each with a volume of $100 \mu \mathrm{L}$ and a density of $2 \times 10^{5}$ cells $/ \mathrm{mL}$, were treated with calcium chloride solutions of concentrations of $100 \mathrm{mM}, 500 \mathrm{mM}$, or $1 \mathrm{M}$ for $5 \mathrm{~min}, 10 \mathrm{~min}$, and $30 \mathrm{~min}$, respectively. After treatments, the cells were washed three times with DMEM, and then $20 \mu \mathrm{L}$ of MTT stock solution was added into each well of both gel-suspended and nonencapsulated cells. After three and half hours incubation in an incubator at a condition of $37^{\circ} \mathrm{C} 0.5 \% \mathrm{CO}_{2}$, all the media were carefully removed, and then $150 \mu \mathrm{L}$ MTT solvent was added into each well. The 96-well plate was then covered with aluminum foil and agitated on an orbital shaker for $15 \mathrm{~min}$, and the absorbance at $590 \mathrm{~nm}$ was measured with a reference filter of $620 \mathrm{~nm}$.

Because of the linear relationship between the absorbance reading of MTT and the number of living cells, the values of absorbance readings were used to represent the number of living cells in each well.

2.5. MTT Assay for Proliferation. Both gel-suspended and non-encapsulated cells were immersed in DMEM (10\% fetal bovine serum) with or without the treatments of calcium chloride solution. MTT stock solution was added in the cell cultures, and the amount of formazan produced was assessed by spectrophotometer as described above. Measurements were made at $6,12,24,48,72$, and 96 hours for the comparison of proliferation of Schwann cells. In this study, 
the densities of cells were $2 \times 10^{5}$ cells $/ \mathrm{mL}, 6 \times 10^{5}$ cells $/ \mathrm{mL}$, or $8.5 \times 10^{5}$ cells $/ \mathrm{mL}$, for investigating the influence of cell density on cell proliferation.

2.6. Rheological Study. Alginate solutions with concentrations of $2 \%(\mathrm{w} / \mathrm{v})$ and $4 \%(\mathrm{w} / \mathrm{v})$ were prepared with DMEM solution, respectively, and Schwann cells were then suspended in alginate solutions at a density of $4 \times$ $10^{5}$ cells $/ \mathrm{mL}, 8 \times 10^{5}$ cells $/ \mathrm{mL}$, or $4 \times 10^{6}$ cells $/ \mathrm{mL}$. The rheological property or viscosities of the cell-alginate mixture were measured by using a rheometer (Brookfield DVIII+ Programmable rheometer, Brookfield, Middleboro, MA, USA). This rheometer has a cone and plate structure with the shear rate being controlled via programming. A CP 41 spindle was selected for use, which required samples of $2 \mathrm{~mL}$. The rheometer also provides the ability to collect and record the data during the rheological tests. The viscosities alginate solution or its mixture with Schwann cells was measured at varying shear rates via the control of the spindle rotation speed sweeping from $10 \mathrm{RPM}$ to $250 \mathrm{RPM}$ in $30 \mathrm{RPM}$ increments. All the measurements were repeated five times.

2.7. Statistical Analysis. Two-way analysis of variance (ANOVA) and Welch's $t$-test (assuming unequal variances) were performed to determine the statistical significance $(P<$ $0.05)$.

\section{Results}

3.1. Cell Survival and Proliferation in Cell Cultures. The goal of paper was to study cell survival and proliferation in the context of alginate hydrogel. Due to the high content of calcium ions involved in crosslinking process, the effect of calcium ions on cell survival and proliferation was studied first using two-dimensional (2D) cell culture in order to understand cell behaviors in a better way. The result is shown in Figure 1. As observed, all the cells in different groups lost half of living cells when treated with calcium solutions. However, the degrees of damage on the remaining cells differed. Thus, the number of living cells treated with $100 \mathrm{mM}$ calcium solution significantly increased $80 \%$ after 24 hours because of the recovery of damaged cells, while the ones in $\left[\mathrm{Ca}^{2+}\right] 1 \mathrm{M}$ group continued to decrease to its $50 \%$, in which most cells were dying within that time period. Although the proliferation rates of the cells treated with the lower calcium concentration were lower than those in the DMEM control group, the increase in number showed that the surviving cells were functionally active.

3.2. Cell Survival and Proliferation in Alginate Hydrogel. The cell density was set to $4 \times 10^{5}$ cells $/ \mathrm{mL}$ in all the experiments presented in this section. Figure 2 shows the numbers of living cells measured at 24 hours after the formation of hydrogel from the cell-alginate cultures with alginate concentrations of $2 \%$ and $4 \%(\mathrm{w} / \mathrm{v})$, respectively, by using calcium chloride solution for crosslinking, as compared to those in control groups (i.e., cells cultured in DMEM medium alone). It is seen that the numbers of living cells in both $2 \%$ and $4 \%$ alginate hydrogels were lower than those in the control group. However, these results showed a greater number of living cells than those in cell cultures from Figure 1 at 24 hours mark.

The results in Figure 2 also show a low survival rate in $4 \%$ alginate solution as compared in $2 \%$ alginate solution, in which the number of living cells was very close to those in DMEM. In the same time, the number of living cells in treated groups in $2 \%$ alginate is higher than those treated groups in DMEM, comparing to Figure 1. These would be discussed more in discussion section.

Figure 3 shows the results, as examined within a longer time period of 96, of cell proliferation in both DMEM and alginate hydrogel with varying cell densities as a continuous study. The initial values of cell numbers in Figure 3 are cell number measured 24 hours after cells being seeded and treated with calcium. The proliferation curve of cells cultured in DMEM medium with cell density of $6 \times 10^{5}$ cells $/ \mathrm{mL}$ was used as the control group in these experiments. As observed, the proliferations of cells in both DMEM and alginate hydrogel were influenced by its cell density. The proliferation rate increased with the cell density. When the cells were cultured at the same density, the proliferation rate of the cells in alginate solution was slower compared to those in DMEM, while the proliferation rate in $4 \%$ alginate hydrogel was slower than the one in $2 \%$ alginate hydrogel. The number of cells in DMEM decreased after certain time periods (50 hours), depending on the cell density.

Cell proliferation was also measured in hydrogels formed by both $2 \%$ and $4 \%(\mathrm{w} / \mathrm{v})$ alginate solution by MTT assay. The results are shown in Figure 4. Alginate solutions were mixed with cells at the density of $8.5 \times 10^{5}$ cells $/ \mathrm{mL}$, and the suspensions were treated with a same procedure mentioned previously. For those encapsulated in $2 \%$ alginate hydrogels (Figure 4(a)), it can be observed that the proliferation rates between two experimental groups have no significant difference during the period of measurements, and both are slower than the control group. However, as for the ones encapsulated in $4 \%$ alginate solution and its hydrogels, the proliferation behavior is very different. Although the experimental groups have lower cell survival rate compared to the ones in $2 \%$ alginate, the numbers of living cells significantly increased after 48 hours incubation with higher proliferation rate compared to the ones in $2 \%$ alginate. Furthermore, the proliferation rate of cells in high calcium concentration hydrogels is higher than the ones in low concentration group and control group.

3.3. Influence of Cell Density on Viscosity. Because the viscosity of the biopolymer solution influences both the scaffold fabrication process and cell damage, the viscosity of alginate solutions with varying cell densities was examined. As seen in Figure 5, the effect of cell density on solution viscosity was significant. Solution viscosity increased with both alginate concentration and cell density and decreased with shear rate. Also, it is seen from Figure 5 that the cells density has different influences on the viscosity of the solution, depending on the alginate concentration. Specifically, the 


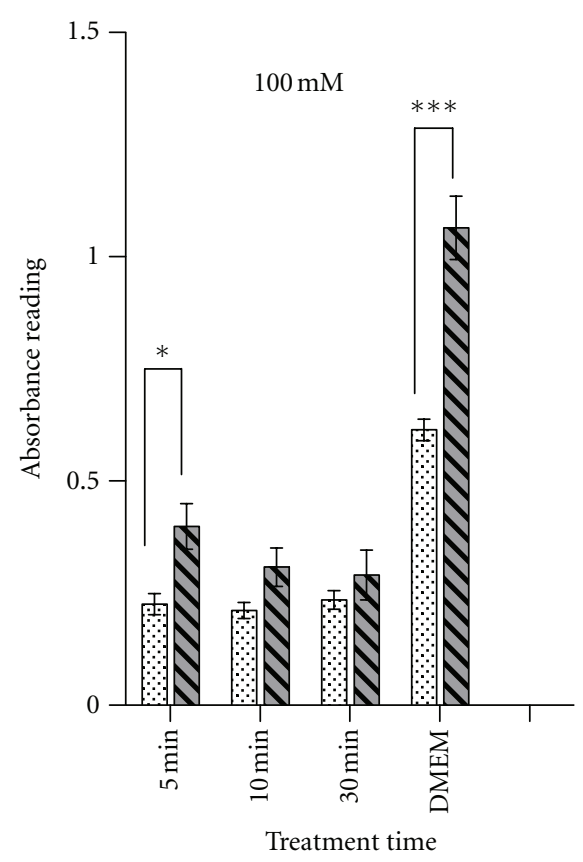

(a)

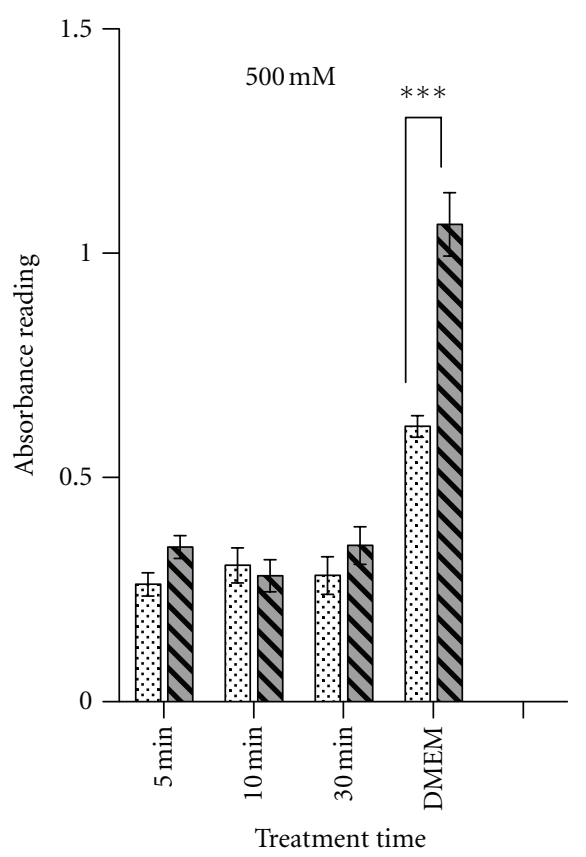

(b)

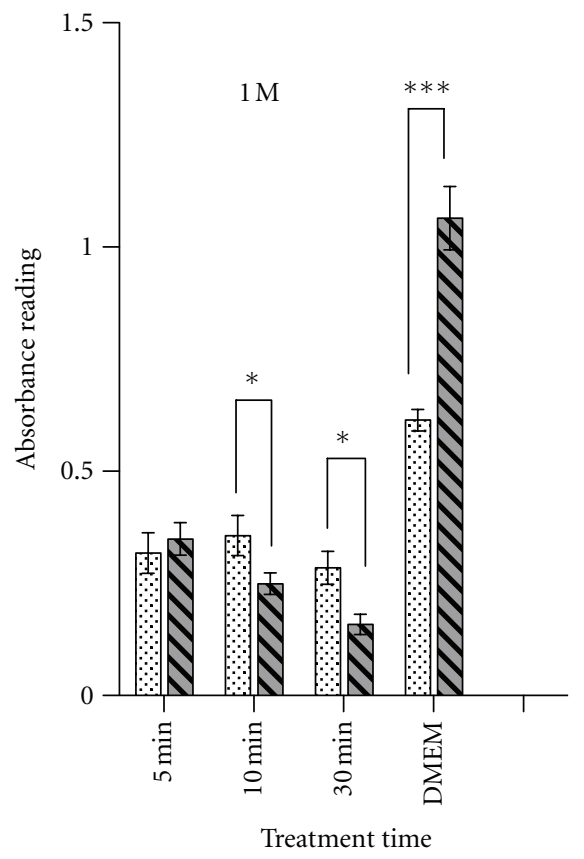

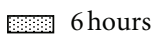

24hours

(c)

FIGURE 1: Result of MTT assay for cell survival and proliferation. (a) $\left[\mathrm{Ca}^{2+}\right] 100 \mathrm{mM}$ treatment, (b) $\left[\mathrm{Ca}^{2+}\right] 500 \mathrm{mM}$ treatment, and (c) $\left[\mathrm{Ca}{ }^{2+}\right]$ $1 \mathrm{M}$ treatment, two-way ANOVA $P<0.05$, Welch's $t$-test, ${ }^{*}$ represents $P<0.05,{ }^{* *}$ represents $P<0.01$, and ${ }^{* * *}$ represents $P<0.001$. 


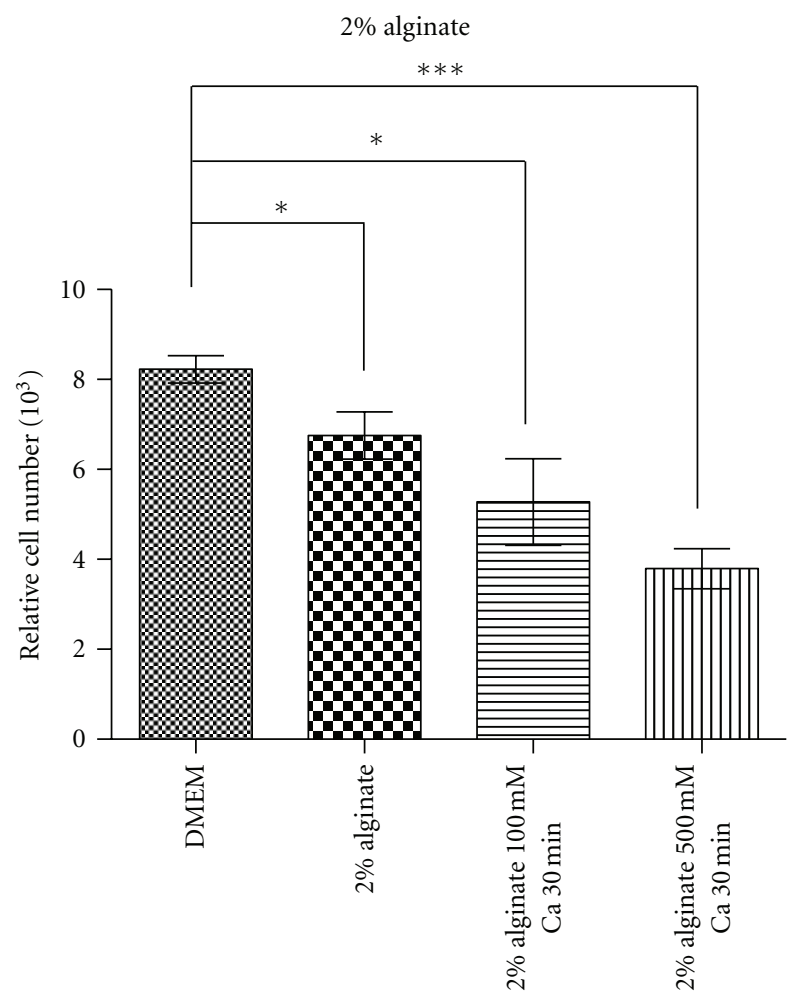

(a)

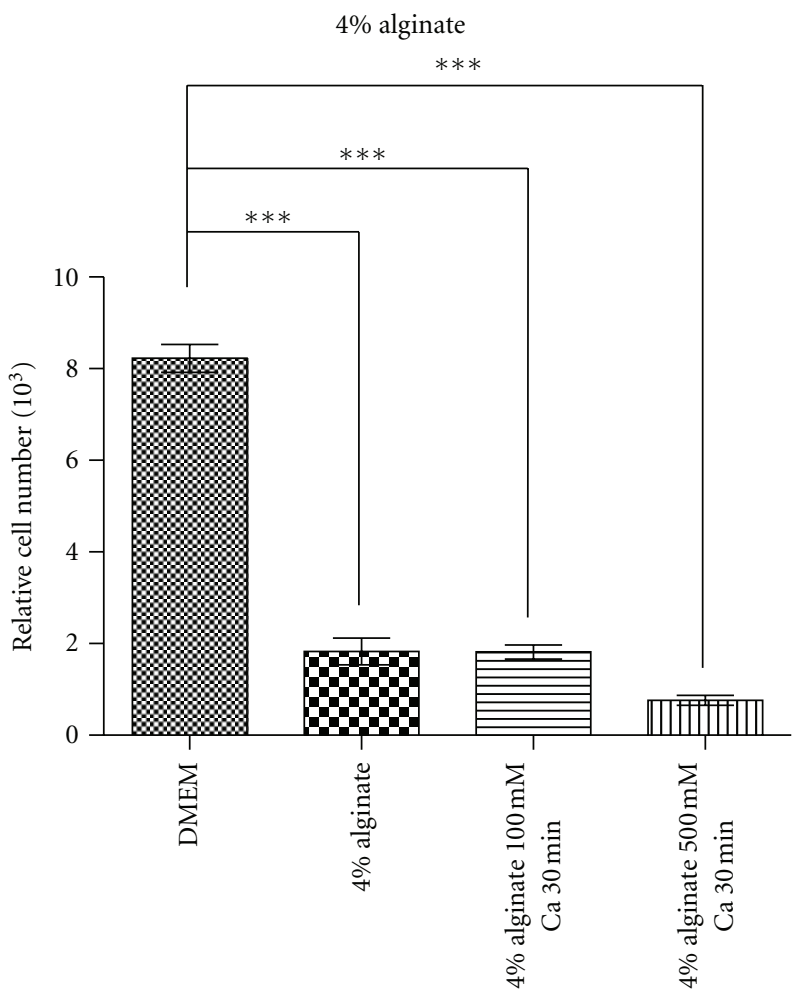

(b)

FIgUre 2: Number of living cells 24 hours after calcium solution treatment in (a) 2\% alginate solution and (b) 4\% alginate solution, ANOVA, $n=8, P<0.05$, Welch's $t$-test, ${ }^{*}$ represents $P<0.05$, ** represents $P<0.01$, and ${ }^{* * *}$ represents $P<0.001$.

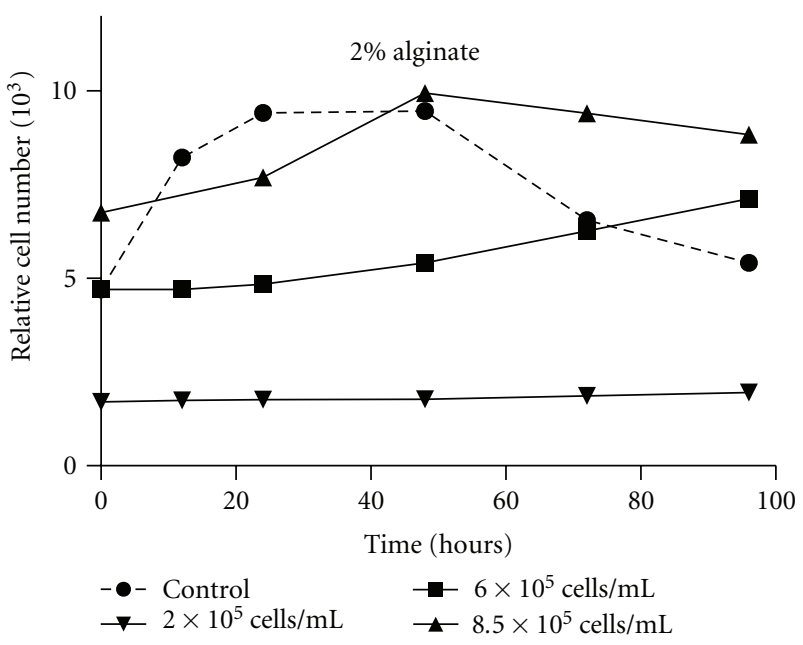

(a)

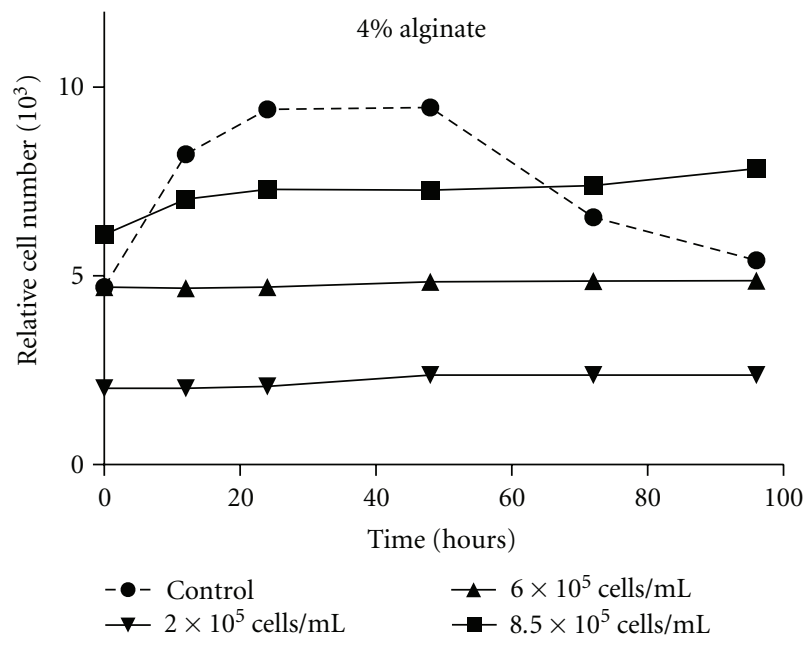

(b)

FIGURE 3: Influence of cell density on encapsulated cells: (a) encapsulated Schwann cells in 2\% alginate, $6 \times 10^{5}$ cells/mL in DMEM as control, (b) encapsulated Schwann cells in $4 \%$ alginate, $6 \times 10^{5}$ cells $/ \mathrm{mL}$ in DMEM as control. 


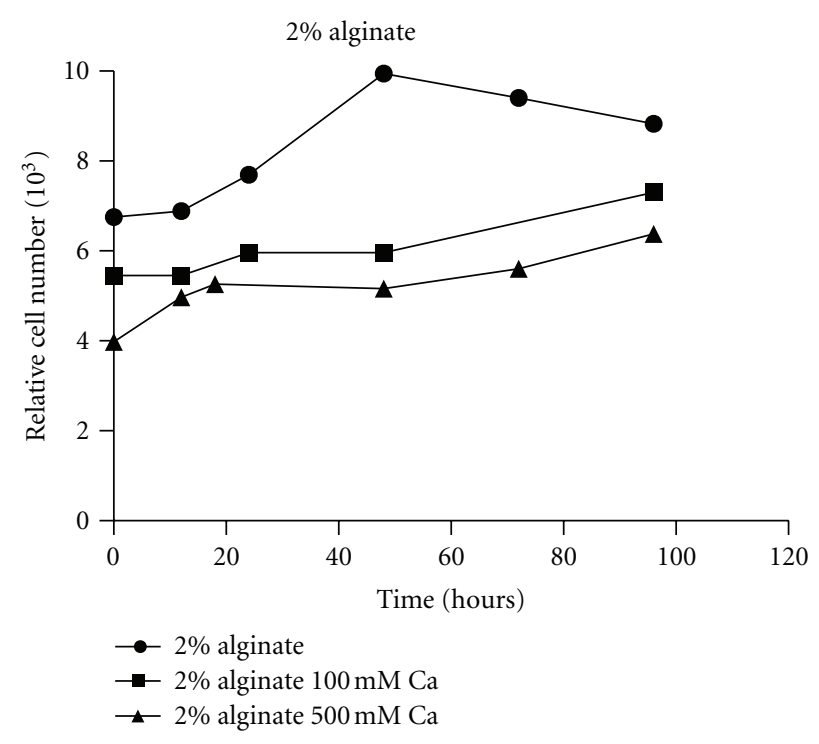

(a)

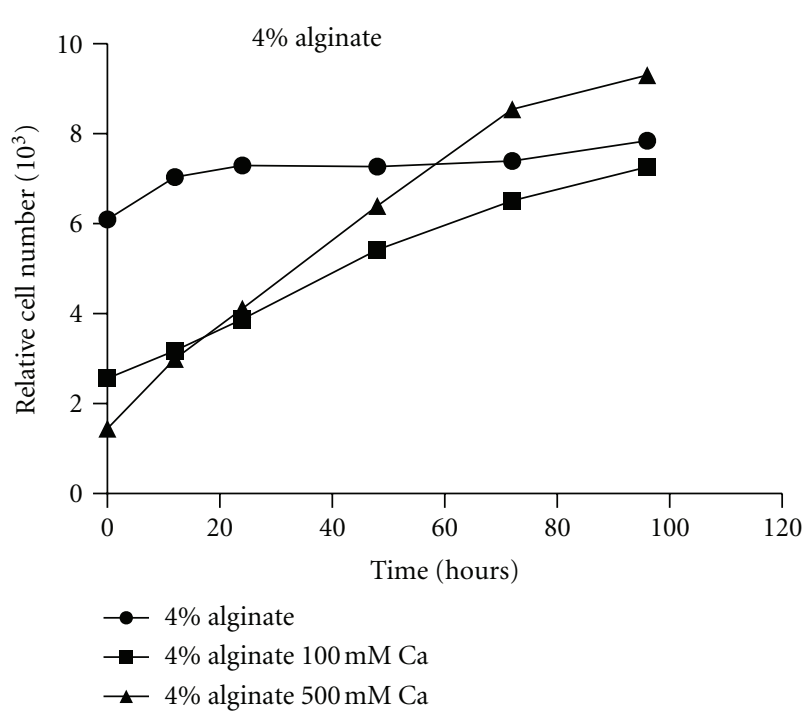

(b)

Figure 4: Proliferation of encapsulated cells; (a) cells in $2 \%$ alginate with calcium treatments, and (b) cells in $4 \%$ alginate with calcium treatments.

increase of cell density caused more increase (percentage) in viscosity on $4 \%$ alginate solution than its effect on $2 \%$ alginate solution.

\section{Discussion}

Cell damage can be caused by various reasons. Depending on the degree of damage, cells can either recover from the damage by its self-repair mechanism or continue to be dysfunctional even to the point of death. In this process, the number of living cells would be balanced in a dynamic between cell death and proliferation. As for Schwann cell lines, the number of living cells should be doubled every 24 hours in a healthy normal proliferation rate. Thus, the number of living cells obtained from the experiments could indicate the degree of cell damage and their proliferation rate.

According to Figure 1, all the cells in different group lost half of living cells when treated with calcium solutions. The damage and cell loss were mainly caused by osmosis effect. However, the degrees of damage on the remaining cells are different. Thus, the number of living cells treated with $100 \mathrm{mM}$ calcium solution significantly increased $80 \%$ after 24 hours because of the recovery of damaged cells, while the ones in $1 \mathrm{M}$ group continued to decrease to its 50\%, in which most cells were dying within that time period. Although the proliferation rates of the cells treated with the lower calcium concentration were lower than those in the DMEM control group, the increasing number of living cells showed that the surviving cells were functionally active. The result also showed that the exposure time has a negative influence on the cell survival, which suggests that the time period of using calcium chloride solution for crosslinking in the fabrication process must be limited.
Calcium ions are considered to be important in eukaryotic cell culture because they are involved with a wide range of vital cell functions including enzyme activities, attachment $[13,14]$, motility, tissue morphology, metabolic processes $[15,16]$, signal transduction $[17,18]$, replication, and electrochemical responses by specialized cells such as muscle and neural cells. By using calcium ion as intracellular messenger, cells walk on a tightrope between life and death. A low calcium concentration $(2 \mathrm{mM})$ must be maintained in the cytoplasm, and, for most cells, calcium is stored in the endoplasmic reticulum (ER). A high calcium concentration is believed to damage the cell membrane by disturbing the state of cell electrolyte. However, because that it is noted in Figure 1 that the losses of living cells in groups treated with $1 \mathrm{M}$ calcium were not different from those treated with $100 \mathrm{mM}$, which is that the concentration should balance the osmosis stress. This result indicated that cell death that happened in this process might be different than necrosis caused by osmosis stress. It is suggested that calcium ions had been used as obligatory signal for programmed cell death (or apoptosis) [19]. This hypothesis can be supported by the continuing cell death observed in Figure 1.

In Figure 2, the result showed that there were more living cells in alginate encapsulation than the number of cells in Figure 1. The reason for this would be either that more cells survived through the calcium treatment in alginateencapsulated environment or that survived cells proliferated much more in 24 hours in order to reach the value that are shown in Figure 2. At the same time, notice that the number of living cells in control group in Figure 2, which has a higher cell density, is actually lower than the number of cells from Figure 1. This result suggests that the first reason would be more likely. Either way this suggests that the use of alginate 


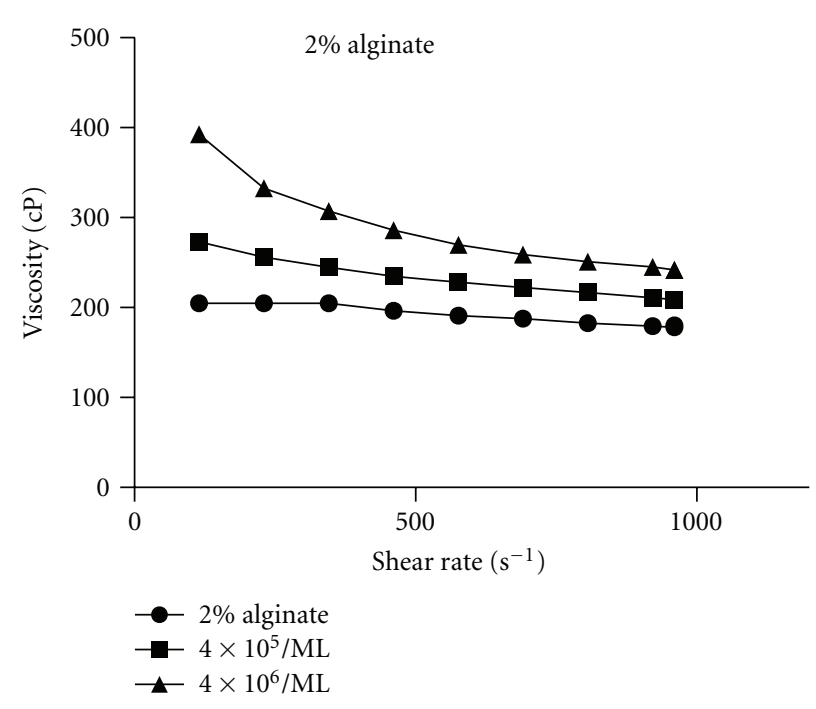

(a)

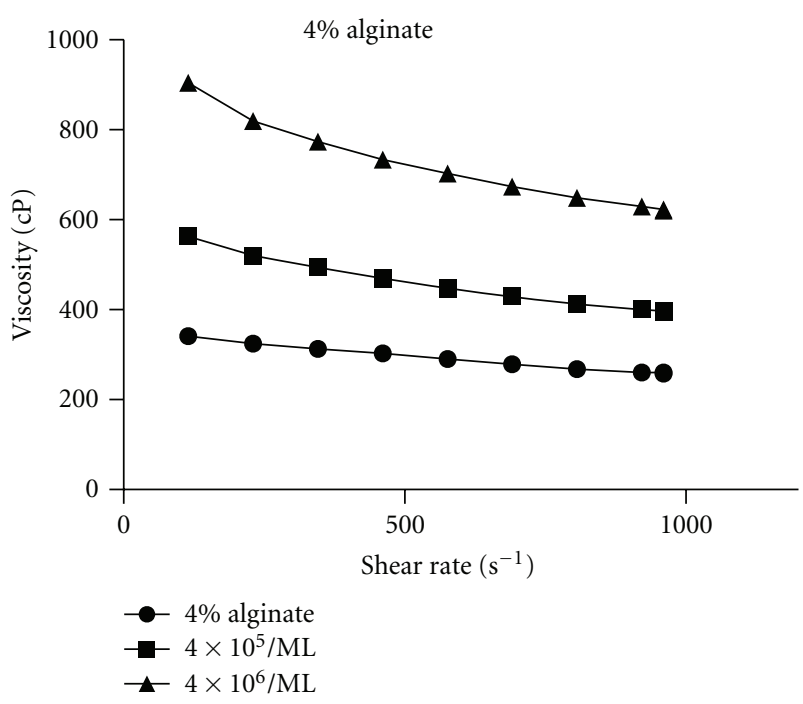

(b)

Figure 5: Effect of cells density on viscosity of cell-alginate mixture with (a) $2 \%$ alginate and (b) $4 \%$ alginate, $n=5, P<0.05$.

provides a more favorable environment for cell survival and proliferation if the cells are exposed to calcium.

The results also show that the numbers of cells are higher in $2 \%$ alginate solution than those in $4 \%$ alginate solution. This is possibly due to the reversible inhibition effect of $4 \%$ alginate solution on cells as previously reported, which might be because of either its physical thickness or the hydrophilic properties of alginate [20]. As observed in the experiment, encapsulated cells rounded up instead of spreading out as they would when cultured in media, and this prevented the formation of cell network and also the interactions between cells. At the same time, cells might lack interaction with alginate gel because of its hydrophilic properties and lack of certain receptions for the proteins on the surface of cell membranes. Nevertheless, the result suggests that low (i.e., $2 \%$ ) concentration alginate solution might be more suitable for cell encapsulation in engineering tissue scaffolds.

Figure 3 showed the proliferation of cells in both DMEM and alginate solution with various cell density. The proliferation rate increased with the cell density, suggesting that cell density has a positive influence on cell proliferation. This might be due to increased cell-cell chemical and biological stimulation for increasing the proliferation rate. When the cells were cultured at the same density, the proliferation rate of the cells in alginate solution was slower compared to those in DMEM, while the proliferation rate in $4 \%$ alginate was slower than the one in $2 \%$ alginate. This showed that the concentration of alginate had a negative influence on cell proliferation. The reason might be that the alginate slows down the absorption and exchanging of ions and proteins in the extracellular environment, and the encapsulated cells were more rounded in alginate and perhaps could not form regular cell-cell interactions as they did in DMEM alone. This is supported by the observation of cells under microscope, that cells in $4 \%$ alginate and $2 \times 10^{5} / \mathrm{mL}$ cells in $2 \%$ alginate rounded up in its gel environment. Even these cells survived, however, were in an unhealthy condition. With increased cell density, the contact between cells increased, thus, the proliferation rate was higher. However, the number of cells in DMEM decreased after 50 hours. This is because the space of the cells on culture plate limited cell growth and also caused competition among these cells for nutrients, which are provided through media changing regularly yet not constantly. Finally cell number decreased because of the lack of nutrients and the great number of metabolism waste. This would be different in an in vivo environment.

In Figure 4, the proliferation of cells in alginate gelsuspension was observed. The ones encapsulated in $4 \%$ alginate solution and its hydrogels, the proliferation behavior is very different. Although the experimental groups have lower cell survival rate compared to the ones in $2 \%$ alginate, the numbers of living cells significantly increased after 48 hour incubation with higher proliferation rate compared to the ones in $2 \%$ alginate. Furthermore, the proliferation rate of cells in high calcium concentration hydrogels is higher than the ones in low concentration group and control group. This surprising result might be due to the exchange of calcium ions, which is an important second messenger signal in cell metabolism, between cells and their extracellular environments, or the changing of the value of $\mathrm{pH}$ in the media as living cells tend to cause during their metabolism, as it has been discussed above.

Figure 5 showed that solution viscosity increased with cell density. The results also illustrate that the relationship between the cell density and the solution viscosity can be affected by the concentration of alginate solution, that is, the higher the concentration, and the more profound effect the cell density has on the solution viscosity. The results present a dilemma situation in the scaffold fabrication, a higher cell density is required for the survival and proliferation 
in calcium abundant after fabrication, which, meanwhile, increases the solution viscosity and the mechanical forces needed in the scaffold fabrication, thus causing more cell damage. As such, further studies are encouraged to determine the cell density mixed in the solution such that desired cell survival proliferation rate can be achieved during the scaffold fabrication process and afterwards. Also, these tests are designed for the dispensing method for the author's lab, and the influence of cells on viscosity for alginate hydrogel particles would be needed for different fabrication techniques.

\section{Conclusions}

The presented study focused on the influence of calcium ions, which was used as crosslinker, on cell viability and proliferation during and after the fabrication process. The influence of calcium concentration and its exposure time were studied on cells cultured in both DMEM and alginate hydrogels. It was found that exposure of cells to the calcium environment can cause significant loss of living cells in media. Although the effect of the difference in the calcium concentration and exposure time on cell survival is not significant as examined at 6 hours, the effect becomes profound at 24 hours. This might be due to the permanent cell damage caused by the high calcium concentration. It was also found that the use of alginate could provide a favorable environment for cell survival and proliferation once exposed to the calcium environment and that the cell viability and proliferation capacity in alginate hydrogel depends on alginate concentration and cell density in addition to the calcium concentration and exposing time. This study illustrated that, by rigorously choosing these process parameters, cell survival and proliferation during and after the biofabrication process can be regulated.

\section{Acknowledgment}

The financial support from the Saskatchewan Health Research Foundation (SHRF) to the present study is acknowledged.

\section{References}

[1] R. Chang, J. Nam, and W. Sun, "Effects of dispensing pressure and nozzle diameter on cell survival from solid freeform fabrication-based direct cell writing," Tissue Engineering A, vol. 14, no. 1, pp. 41-48, 2008.

[2] M. G. Li, X. Y. Tian, and X. B. Chen, "A brief review of dispensing-based rapid prototyping techniques in tissue scaffold fabrication: role of modeling on scaffold properties prediction," Biofabrication, vol. 1, no. 3, Article ID 032001, 2009.

[3] M. Li, X. Tian, N. Zhu, D. J. Schreyer, and X. Chen, "Modeling process-induced cell damage in the biodispensing process," Tissue Engineering C, vol. 16, no. 3, pp. 533-542, 2010.

[4] K. C. Yan, K. Nair, and W. Sun, "Three dimensional multi-scale modelling and analysis of cell damage in cellencapsulated alginate constructs," Journal of Biomechanics, vol. 43, no. 6, pp. 1031-1038, 2010.
[5] A. Mosahebi, M. Simon, M. Wiberg, and G. Terenghi, "A novel use of alginate hydrogel as Schwann cell matrix," Tissue Engineering, vol. 7, no. 5, pp. 525-534, 2001.

[6] L. A. Pfister, E. Alther, M. Papalö̈zos, H. P. Merkle, and B. Gander, "Controlled nerve growth factor release from multiply alginate/chitosan-based nerve conduits," European Journal of Pharmaceutics and Biopharmaceutics, vol. 69, no. 2, pp. 563$572,2008$.

[7] D. Suárez-González, K. Barnhart, E. Saito, R. Vanderby, S. J. Hollister, and W. L. Murphy, "Controlled nucleation of hydroxyapatite on alginate scaffolds for stem cell-based bone tissue engineering," Journal of Biomedical Materials Research A, vol. 95, no. 1, pp. 222-234, 2010.

[8] G. Turco, E. Marsich, F. Bellomo et al., "Alginate/hydroxyapatite biocomposite for bone ingrowth: a trabecular structure with high and isotropic connectivity," Biomacromolecules, vol. 10, no. 6, pp. 1575-1583, 2009.

[9] S. F. Lan, B. Safiejko-Mroczka, and B. Starly, "Long-term cultivation of HepG2 liver cells encapsulated in alginate hydrogels: a study of cell viability, morphology and drug metabolism," Toxicology in Vitro, vol. 24, no. 4, pp. 1314-1323, 2010.

[10] D. O. de Lima, C. G. Aimoli, and M. M. Beppu, "Investigation on the biomimetic influence of biopolymers on calcium phosphate precipitation-part 1: alginate," Materials Science and Engineering C, vol. 29, no. 4, pp. 1109-1113, 2009.

[11] H. Tabesh, G. Amoabediny, N. S. Nik et al., "The role of biodegradable engineered scaffolds seeded with Schwann cells for spinal cord regeneration," Neurochemistry International, vol. 54, no. 2, pp. 73-83, 2009.

[12] E. Goto, M. Mukozawa, H. Mori, and M. Hara, "A rolled sheet of collagen gel with cultured Schwann cells: model of nerve conduit to enhance neurite growth," Journal of Bioscience and Bioengineering, vol. 109, no. 5, pp. 512-518, 2010.

[13] J. Lawler, R. Weinstein, and R. O. Hynes, "Cell attachment to thrombospondin - the role of Arg-Gly-Asp, calcium, and integrin receptors," Journal of Cell Biology, vol. 107, no. 6, pp. 2351-2361, 1988.

[14] E. A. Abou Neel, G. Palmer, J. C. Knowles, V. Salih, and A. M. Young, "Chemical, modulus and cell attachment studies of reactive calcium phosphate filler-containing fast photocuring, surface-degrading, polymeric bone adhesives," Acta Biomaterialia, vol. 6, no. 7, pp. 2695-2703, 2010.

[15] A. Rimessi, C. Giorgi, P. Pinton, and R. Rizzuto, "The versatility of mitochondrial calcium signals: from stimulation of cell metabolism to induction of cell death," Biochimica et Biophysica Acta, vol. 1777, no. 7-8, pp. 808-816, 2008.

[16] M. Murgia, C. Giorgi, P. Pinton, and R. Rizzuto, "Controlling metabolism and cell death: at the heart of mitochondrial calcium signalling," Journal of Molecular and Cellular Cardiology, vol. 46, no. 6, pp. 781-788, 2009.

[17] V. Chattree, N. Khanna, and D. N. Rao, "Alterations in T cell signal transduction by $\mathrm{M}$. leprae antigens is associated with downregulation of second messengers PKC, calcium, calcineurin, MAPK and various transcription factors in leprosy patients.," Molecular Immunology, vol. 44, no. 8, pp. 20662077, 2007.

[18] J. Xu, C. Wang, R. Han et al., "Evidence of reciprocal regulation between the high extracellular calcium and RANKL signal transduction pathways in RAW cell derived osteoclasts," Journal of Cellular Physiology, vol. 202, no. 2, pp. 554-562, 2005. 
[19] N. Demaurex and C. Distelhorst, "Cell biology: apoptosisthe calcium connection," Science, vol. 300, no. 5616, pp. 65-67, 2003.

[20] N. C. Hunt, R. M. Shelton, and L. M. Grover, "Reversible mitotic and metabolic inhibition following the encapsulation of fibroblasts in alginate hydrogels," Biomaterials, vol. 30, no. 32, pp. 6435-6443, 2009. 

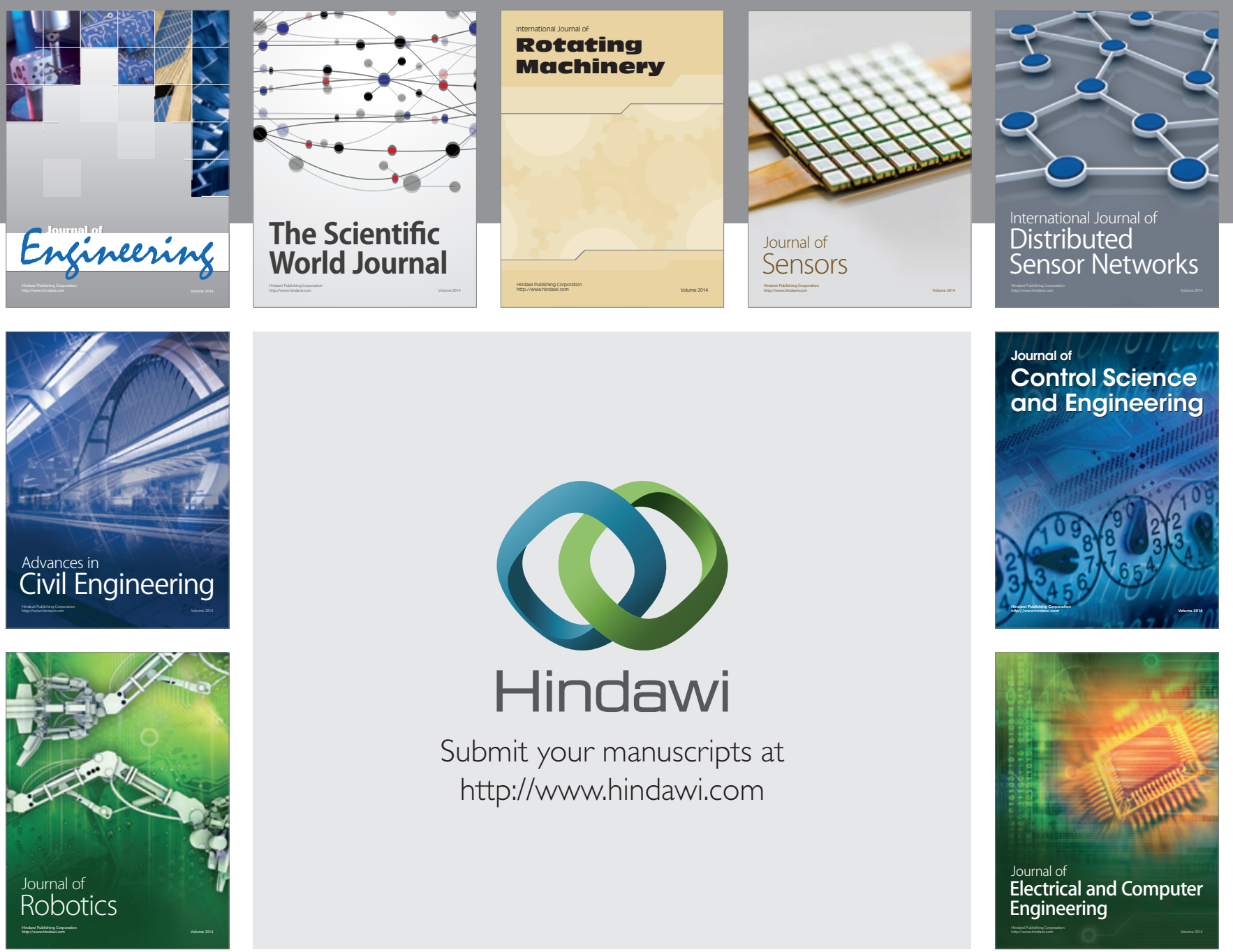

Submit your manuscripts at

http://www.hindawi.com
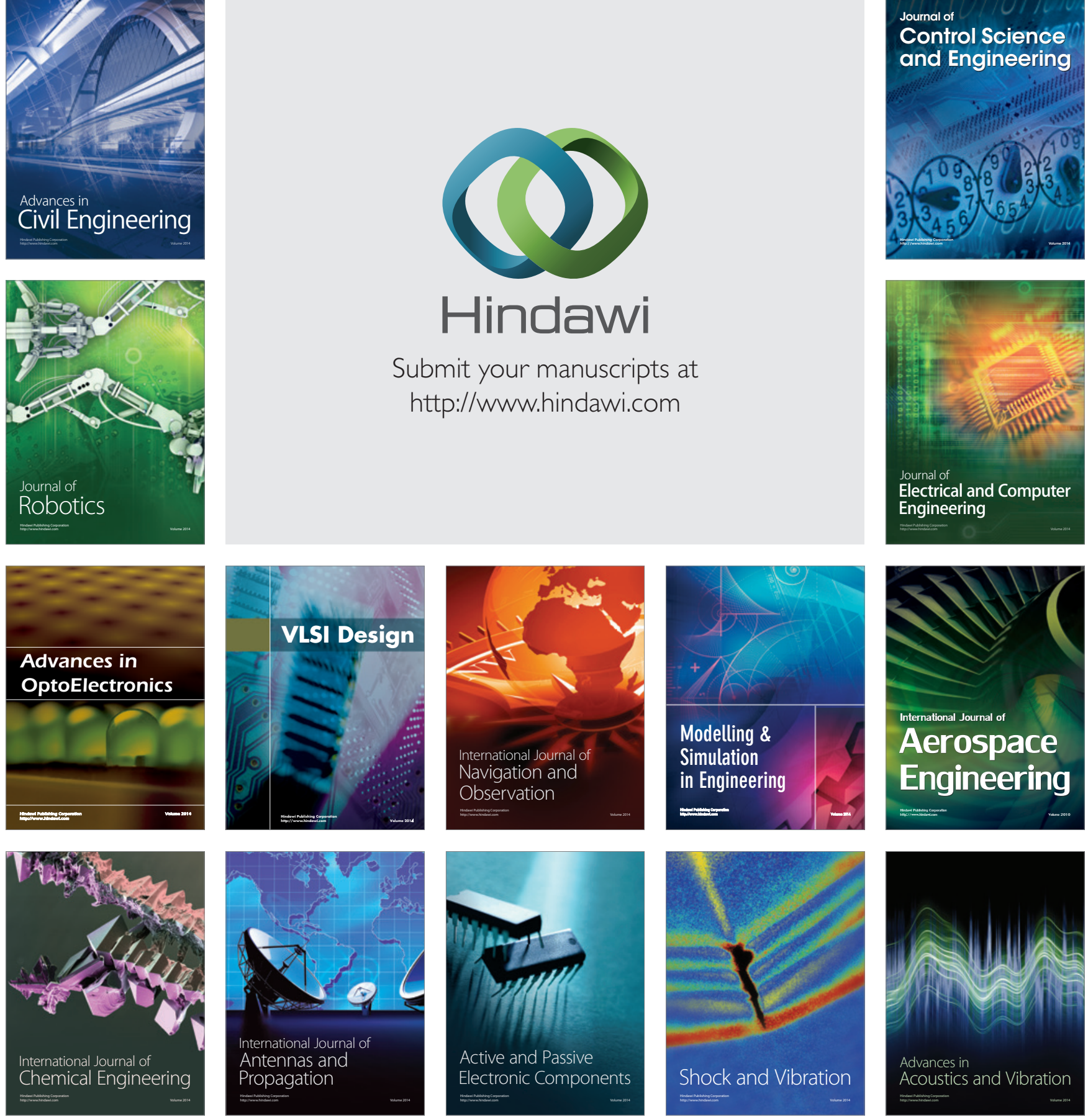